\title{
50 yaş ve üzeri hastalarda üst gastrointestinal sistem konvansiyonel radyografik görüntülemelerinin değerlendirilmesi
}

\section{Evaluation of upper gastrointestinal system conventional radiographies in} patients over 50 years of age

\author{
Emine Sumru Savaş ${ }^{1}$ (i) \\ Abdullah Uysal ${ }^{2}$ iD \\ Nevra Elmas ${ }^{2}$ \\ Zeliha Fulden Saraç ${ }^{1}$ \\ Selahattin Fehmi Akçiçek ${ }^{1}$ \\ ${ }^{1}$ Ege Üniversitesi Tıp Fakültesi İç Hastalıkları Anabilim Dalı, Geriatri Bilim Dalı, İzmir, Türkiye \\ ${ }^{2}$ Ege Üniversitesi Tıp Fakültesi Radyoloji Anabilim Dalı, İzmir, Türkiye
}

Öz

Amaç: Yaşlanma ile ortaya çıkan gastrointestinal sistem (GiS) değişiklikleri sıktır. Bu değişikliklerin bazıları fizyolojik olmakla birlikte, bazı değişiklikler patolojik olup ileri yaşta sık görülür. Bu çalışmada; 50 yaş ve üzeri hastalarda üst GiS konvansiyonel radyografik görüntülemelerin değerlendirilmesi amaçlanmıştır.

Gereç ve Yöntem: Ocak 2011 - Aralık 2012 tarihleri arasında hastanemize başvuran hastalardan, üst GiS şikayetleri nedeniyle Radyoloji Bölümü Radyoskopi birimine yönlendirilerek özofagografi, çift kontrastlı mide-duodenum grafisi ve özofagus-mide-duodenum grafileri çekilmiş 50 yaş üzerindeki hastaların hastane kayıtları retrospektif olarak değerlendirilmiştir.

Bulgular: Üst GiS radyografileri çekilen 2130 hastadan 50 yaş ve üzeri olan 1126 hastanın; \%62'si 50-64 yaş, \%32,6'sı 65-79 yaş aralığında, $\% 5,4$ 'ü ise 80 yaş ve üzerinde bulunmuştur. Radyografilerinde normal dışı bulgu tespit edilen $(\% 55,2)$ hastalarda; gastroözofageal reflü (GÖR) $(\% 9,8)$, tersiyer kontraksiyon $(\% 9,2)$, opere olgular $(\% 8,6)$, kontur düzensizliği $(\% 8,3)$, hiatus hernisi $(\% 6,7)$, akalazya $(\% 6)$, divertiküller $(\% 5)$, özofageal veb $(\% 1,8)$ ve bu gruplarda sınıflanamayan diğer patolojiler $(\% 8,7)$ tespit edilmiştir. Bazı hastalarda birden fazla patolojik bulgu saptanmıştır.

Sonuç: Elli yaş ve üzeri hastalarda konvansiyonel radyografik görüntülemeler ile tespit edilen en sık normal dışı bulgular GÖR ve tersiyer kontraksiyon olarak tespit edilmiştir. Yaş aralığı yükseldikçe patolojik bulguların oranının arttığı görülmektedir.

Anahtar Sözcükler: Üst gastrointestinal sistem, yaşlı, prevalans, radyografi.

\begin{abstract} retrospectively.

\footnotetext{
Sorumlu yazar: Emine Sumru Savaş

Ege Üniversitesi Tıp Fakültesi İç Hastalıkları Anabilim Dalı,

Geriatri Bilim Dalı, İzmir, Türkiye

E-posta: esumrusavas@yahoo.com

Başvuru Tarihi: 20.12.2019 Kabul Tarihi: 24.04.2020
}

Aim: The gastrointestinal (Gl) changes related to aging are common. Some of these changes are physiological. However, pathological changes are also frequent at advanced age. The aim of this study was to evaluate upper Gl conventional radiographic imagings in patients over 50 years of age.

Materials and Methods: Patients over 50 years of age who were referred to Radioscopy Division of Radiology Department between January 2011 and December 2012, and underwent esophagography, and double contrast upper gastrointestinal series for upper Gl symptoms were evaluated 
Results: Out of 2130 patients who underwent upper Gl radiographic imaging, 1126 were over 50 years of age. The ratio of patients in 50-64, 65-79 age ranges, and patients $\geq 80$ years of age were $62 \%, 32.6 \%$, and 5.4\%, respectively. There were; gastroesophageal reflux disease (GERD) (9.8\%), tertiary contractions (9.2\%), postoperative changes (8.6\%), mucosal irregularity (8.3\%), hiatus hernia (6.7\%) achalasia (6\%), diverticulum (5\%), esophageal web (1.8\%) and others which were not classified elsewhere (8.7\%) among patients with abnormal radiological findings (55.2\%). More than one pathology was detected in some patients.

Conclusion: The most common abnormal findings were GERD and tertiary contractions among patients over 50 years of age who underwent upper Gl conventional radiographic imaging. As age increases, the prevalence of pathological findings also increases.

Keywords: Upper gastrointestinal tract, aged, prevalence, radiography.

\section{Giriş}

Tüm dünyada yaşam beklentisi artmaktadır. Yaşlanma sürecindeki değişiklikler, ırka ait faktörler, cinsiyet, sosyoekonomik durum gibi pek çok faktör yaşlanma algısını ve yaşlının sağlık durumunu etkilemektedir (1-3).

Yaşlanmayla birlikte bazı hastalıkların prevalansı da artmakta ve yaşıının yaşam kalitesini etkilemektedir. Yaşlanmayla meydana gelen değişikliklerden, gastrointestinal sistem (GiS) ile ilgili olarak; motilite, enzim ve hormon sekresyonu, sindirim ve emilim fonksiyonlarındaki değişiklikler oldukça sık olarak görülmektedir. Bu değişikliklerin bazıları fizyolojik olmakla birlikte, bazı değişiklikler patolojik olup 65 yaş üzeri bireylerde sık olarak tespit edilir. Ayrıca, ileri yaşa sınırı ve ileri yaşa özgün GiS ilişkili hastalıklar mevcut olmamakla birlikte bazı hastalıklar bu yaş grubunda daha sık görülür (3).

Her ne kadar beklenen yaşam süresinin artması ile yaşı tanımı için kullanılan kesme noktalarının yükselebileceği düşünülse de yaşlı tanımı 65 yaş ve üzeri kişileri kapsamaktadır (3). Türkiye'de yaşlı bireylerin topluma oranı 2019 'da $\% 9,1$ olmuştur (4). Amerika'da ise \%14,5 olarak tespit edilmiştir (5). Yaşı popülasyon içinde en hızı artan yaş grubu ise 80 yaş ve üzeri gruptur (6). Türk popülasyonu için bu yaş gruplarına ait üst GiS hastalıkları ile ilgili epidemiyolojik veriler yetersizdir.

$\mathrm{Bu}$ nedenlerle; hastanemiz Radyoloji Anabilim Dalı Radyoskopi birimine sevk edilen hastalardan 50 yaş ve üzeri olan bireylerin özofagografi, mide-duodenum grafisi ve özofagus-mideduodenum (ÖMD) grafisi sonuçlarını retrospektif olarak değerlendirerek üst GiS şikayetleri ile başvuran hastalara radyografik olarak konulan tanıları ve sıklıklarını ortaya koymayı amaçladık.

\section{Gereç ve Yöntem}

$\mathrm{Bu}$ çalışma, retrospektif, kesitsel bir çalışma olarak planlanmıştır. Ocak 2011-Aralık 2012 tarihleri arasında üniversite hastanemiz Radyoloji Anabilim Dalı Radyoskopi ünitesine yönlendirilen hastaların hastane kayıtları incelenmiştir. $\mathrm{Bu}$ hastalardan üst GiS şikayetleri nedeniyle; özofagografi (faringoözofagografiler tüm metinde özofagografi olarak geçmektedir. Bu çalışmada orofarengeal disfaji gibi oral kavite sorunları amaçlanmadığı için bu veriler incelenmemiştir), çift kontrastlı mide-duodenum grafisi ve ÖMD grafileri çekilen hastalar değerlendirilerek 50 yaş ve üzeri olan olgular çalışmaya alınmıştır. Tespit edilen 50 yaş üzeri olguların radyografi raporlarının incelenmesi ile patolojik bulgular ve sıklıkları belirlenmiştir. Elli yaşın altındaki bireyler ve raporları sisteme işlenmemiş olan hastalar çalışma dışı bırakılmıştır.

İncelenen hastalar 50-64 yaş, 65-79 yaş ve 80 yaş ve üzeri olmak üzere üç yaş grubuna, ayrıca 65 yaş üzeri ve altındaki hastalar olarak da iki gruba ayrılmıştır. Radyografilerdeki patolojik bulgular 10 grupta sınıflanmıştır; normal bulgular, gastroözofageal reflü (GÖR), tersiyer kontraksiyon, opere olgular, kontur düzensizliği (dıştan bası, segmente lümen ve kontur düzensizliği bu grupta değerlendirilmiştir), hiatus hernisi, akalazya, divertikül, özofageal veb ve diğerleri (maligniteler, hipotonik mide, kaskad mide, aksiyel rotasyon, duplikasyon kisti, gastrik volvulus, peptik ülser gibi sayıları az olan patolojik bulgular bu gruba dahil edildi).

Bu çalışma, Ege Üniversitesi Tıbbi Araştırmalar Etik Kurulu'ndan onay alınarak, bu kurallar uyarınca yürütülmüştür (Etik kurul karar no: 1912T-36). Veriler sayı (n), ve yüzde (\%) olarak verilmiştir. Kategorik veriler Pearson ki-kare testi ile karşılaştırılmış, $p<0.05$ değerler anlamlı kabul edilmiştir. Çalışma verileri ile ilgili istatistiki 
analizler IBM SPSS Statistics v.18.0 (SPSS Inc, Chicago, Illinois A.B.D.) yazılımı ile yapılmıştır.

\section{Bulgular}

Ege Üniversitesi Tıp Fakültesi Hastanesi Radyoloji Anabilim Dalına bağlı Radyoskopi birimine Ocak 2011-Aralık 2012 aralığında GiS şikayetleri nedeniyle konvansiyonel radyografi çekilmek üzere 6147 hasta sevk edilmiştir. Bu hastalardan 2130 hasta üst GiS semptomları ile başvurmuş olup, bu hastalara özofagografi, çift kontrastlı mide-duodenum grafisi ve ÖMD grafileri çekilmiştir.

Bu kişilerden 1126 hasta 50 yaş ve üzeri olarak tespit edilmiştir. Çalışmaya alınan 1126 olgunun $\% 55$ 'i kadın ve \%45'i erkektir. Her iki cinsiyette de yaş aralığı yükseldikçe hasta sayısı azalmaktadır. Hastaların yaş dağılımına bakıldığında; 50-64 yaş aralığındakilerin oranı $\% 62,65-79$ yaş aralığındaki hastalar \%32,6, 80 yaş ve üzerindekilerin oranı ise $\% 5,4$ olarak bulunmuştur. Geriatrik yaş grubu olan 65 yaş ve üzeri hastaların oranı \%38'dir. Hastaların yaş ortalaması $62,7 \pm 9,1$ olup en yaşlı hasta 92 yaşındadır. En fazla hasta 50-64 yaş grubundadır ve bu grupta kadın hastalar daha fazladır $(p<0,001)$. Yaş aralıklarına ve cinsiyete göre hastaların dağılımı Tablo-1'de gösterilmektedir (Tablo-1). Radyoskopi birimine sevk edilen hastalardan üst GiS şikayetleri için klinisyenler tarafından 648 hastaya $(\% 57,5)$ sadece özofagografi, 325 hastaya $(\% 28,9)$ mideduodenum grafisi ve 153 hastaya $(\% 13,6)$ ÖMD istenmiştir.

Tablo-1. Yaş gruplarının cinsiyete göre dağılımı.

\begin{tabular}{lllll}
\hline Parametreler & & Kadın $(\mathbf{n = 6 1 9 )}$ & Erkek $(\mathbf{n = 5 0 7 )}$ & $\begin{array}{l}\text { Toplam } \\
(\mathbf{n = 1 1 2 6})\end{array}$ \\
\hline & $50-64$ yaş & $418(37,1)$ & $280(24,9)$ & $698(62)$ \\
Yaş grupları & 65-79 yaş & $171(15,2)$ & $196(17,4)$ & $367(32,6)$ \\
& $\geq 80$ yaş & $30(2,7)$ & $31(2,8)$ & $61(5,4)$ \\
\hline
\end{tabular}

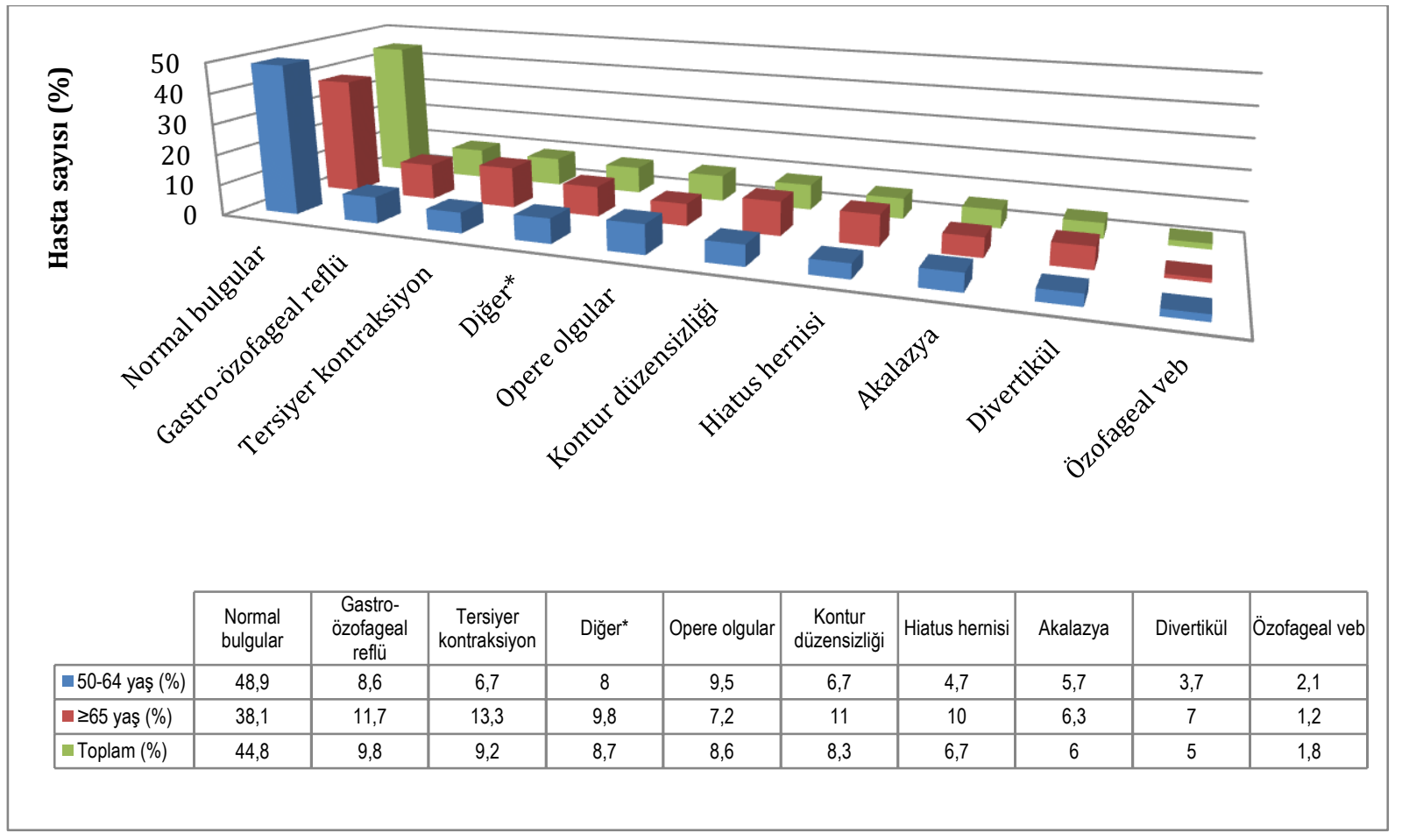

*Diğer bulgular; maligniteler, hipotonik mide, kaskad mide, aksiyel rotasyon, duplikasyon kisti, gastrik volvulus, peptik ülser gibi patolojik bulgular.

Şekil-1. Radyolojik bulguların yaş gruplarına göre dağılımı. 


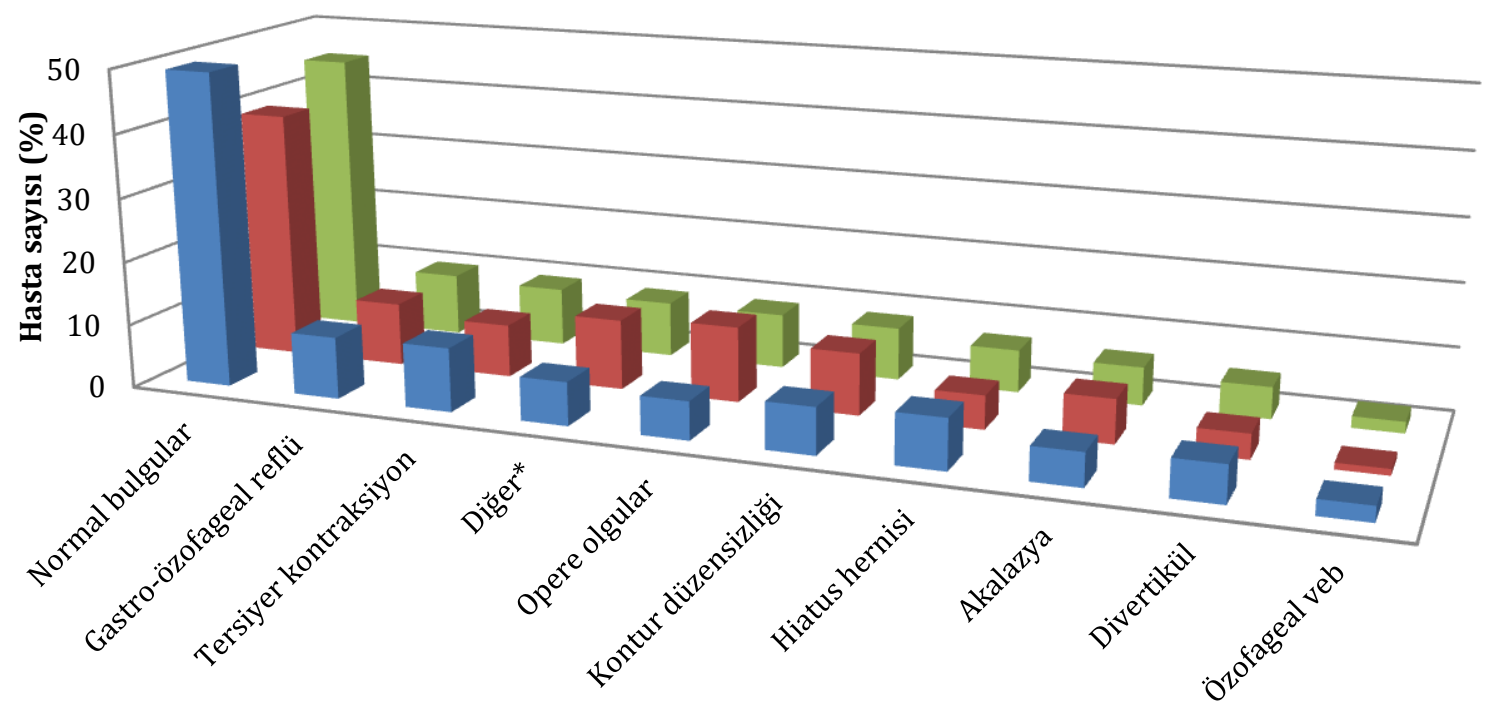

\begin{tabular}{|c|c|c|c|c|c|c|c|c|c|c|}
\hline & $\begin{array}{l}\text { Normal } \\
\text { bulgular }\end{array}$ & $\begin{array}{c}\text { Gastro- } \\
\text { özofageal } \\
\text { reflü } \\
\end{array}$ & $\begin{array}{c}\text { Tersiyer } \\
\text { kontraksiyon }\end{array}$ & Diğer* & Opere olgular & $\begin{array}{c}\text { Kontur } \\
\text { düzensizliği }\end{array}$ & Hiatus hernisi & Akalazya & Divertikül & $\begin{array}{c}\text { Özofageal } \\
\text { veb }\end{array}$ \\
\hline - Kadın (\%) & 49,4 & 9,7 & 10 & 6,8 & 6 & 7,3 & 7,9 & 5,2 & 5,8 & 2,4 \\
\hline Erkek (\%) & 39,1 & 9,9 & 8,3 & 11 & 11,8 & 9,7 & 5,3 & 6,9 & 3,9 & 1 \\
\hline Toplam (\%) & 44,8 & 9,8 & 9,2 & 8,7 & 8,6 & 8,3 & 6,7 & 6 & 5 & 1,8 \\
\hline
\end{tabular}

${ }^{*}$ Diğer bulgular; maligniteler, hipotonik mide, kaskad mide, aksiyel rotasyon, duplikasyon kisti, gastrik volvulus, peptik ülser gibi patolojik bulgular.

Şekil-2. Radyolojik bulguların cinsiyete göre dağılımı

Değerlendirilen 1126 olguda radyografi raporları $\% 44,8$ oranında normal sınırlarda bulundu. En sık saptanan patolojik bulgular olan GÖR ve tersiyer kontraksiyon, sırasıyla $\% 9,8$ ve $\% 9,2$ hastada görüldü. Bazı hastalarda birden fazla patolojik bulgu saptandı.

Yaş ilerledikçe patoloji sıklığı artmaktadır; 50-64 yaş grubu radyografilerinde $\% 51,1$ oranında, 65 79 yaş grubunda $\% 59,7,80$ yaş ve üzeri grupta $\% 75,4$ oranında normal dışı bulgu saptanmış olup, tüm 65 yaş ve üzeri grupta bu oran $\% 61,9$ 'dur $(p<0,001)$. En yaşlı grup olan 80 yaş ve üzeri grupta az sayıda hasta olması nedeniyle radyolojik bulgular yaş grupları yönünden 65 yaş altı ve üstü hastalarda değerlendirildi.

Yaş grupları geriatrik ve 65 yaş altı olarak sınıflandığında yaş gruplarında saptanan bulgular Şekil-1'de görülmektedir (Şekil-1). Radyolojik bulgular her iki grupta karşılaştırıldığında; geriatrik yaş grubunda 50-64 yaş grubuna göre; tersiyer kontraksiyon $(p<0,001)$, kontur düzensizliği $(p=0,012)$, hiatus hernisi $(p=0,001)$ ve divertiküller $(p=0,014)$ anlamlı olarak daha fazla; normal bulgular ise anlamlı olarak daha az saptanmıştır $(p<0,001)$. Yaş grupları incelendiğinde; 50-64 yaş grubunda normal bulgulardan sonra en sık saptanan radyolojik bulgular opere olgular ve GÖR'dür (sırasıyla; \%48,9, \%9,5, \%8,6). Geriatrik yaş grubunda en sık saptanan ilk üç bulgu ise sırasıyla normal bulgular $(\% 38,1)$, tersiyer kontraksiyon $(\% 13,3)$ ve GÖR'dür $(\% 11,7)$.

Normal bulgular kadın hastalarda anlamlı olarak daha fazla iken $(p<0,001)$ diğer bulgular ve opere olgular erkek hastalarda anlamlı olarak daha fazla bulundu $(p=0,012$ ve $p<0,001)$. Cinsiyete göre patolojiler ve sıklıkları Şekil-2'de verilmektedir (Şekil-2).

En sık saptanan patoloji olan GÖR, en sık 65-79 yaş arasında görülmüştür $(\% 11,7)$. En yaşlı grup olan 80 yaş ve üzeri grupta normal bulgulardan sonra en sık bulgular tersiyer kontraksiyon (\%18), hiatus hernisi (\%18), GÖR $(\% 11,5)$ ve divertiküldür $(\% 11,5)$. 


\section{Tartışma}

İki yıllık süre içinde Gis şikayetleri ile başvuruları sonucu konvansiyonel radyografi çekilmek üzere yönlendirilen 6147 hastayı tarayarak 50 yaş ve üzeri 1126 kişinin radyografilerini değerlendirmeye aldığımız çalışmamızda; normal bulgular \%44,8 oranında ve en sık iki tanıdan GÖR \%9,8 oranında, tersiyer kontraksiyon ise $\% 9,2$ oranında saptanmıştır. Yaş ilerledikçe tespit edilen normal bulgu oranı anlamlı şekilde azalırken, tersiyer kontraksiyon, kontur düzensizliği, hiatus hernisi ve divertikül oranları artış göstermiştir. Yaş gruplarında en sık radyolojik bulgular; 50-64 yaş grubunda normal bulgular, opere olgular ve GÖR, geriatrik yaş grubunda ise normal bulgular, tersiyer kontraksiyon ve GÖR olarak saptanmıştır.

Üst GiS rahatsızlıkları yaşlanmayla birlikte sıkça karşılaşılan durumlardır. Epidemiyolojik ve klinik çalışmalarda üst GiS hastalıklarının özellikle yaşı kişilerde daha yüksek olduğu gösterilmiştir $(7,8)$. Benzer bir şekilde, bizim çalışmamızda da yaş ilerledikçe patoloji sıklığı artmaktadır; 50-64 yaş grubu radyografilerinde $\% 51,1$ oranında, $65-79$ yaş grubunda $\% 59,7$ ve 80 yaş ve üzeri grupta $\% 75,4$ oranında patolojik bulgu saptanmıştır. Ayrıca, yaşılıarda üst GiS hastalıklarının semptomlara dayalı olarak tanısı oldukça zordur ve yanıltıcı olabilir (8). Peptik ülser veya GÖR gibi rahatsızlıkları olan yaşlıların tipik semptomları bildirme oranlarının düşük olduğu ve yaşlı hastalarda nonspesifik semptomların olmasının, yaşlılarda geç tanı konmasının en önemli nedenlerinden biri olduğu bildirilmiştir (8, 9). Diğer yandan, çoğu yaşlı hasta üst Gis hastalıkları ile ilişkilendirilememiş üst GiS semptomları bildirmektedir (10). Yaşılıarda meydana gelen fizyolojik değişiklikler, mevcut hastalıklar ve kullandıkları ilaçlar gibi durumların ve fonksiyonel durumlarının semptomları algılamalarını ve hekime başvurularını etkileyebildiği belirtilmektedir $(8,11)$. Yaşlılarda üst GiS semptomları ile klinik ve fonksiyonel durumlarını araştıran geniş çaplı bir araştırmada; yaşı hastalarda üst GiS semptomları ile klinik ve fonksiyonel özelliklerinin ilişkili olduğu gösterilmiştir (8). Bahsi geçen çalışmada Pilotto ve arkadaşları; 60 yaş üzeri 3238 hastada üst GiS semptomları ile üst GiS hastalığı varlığını hasta beyanına dayalı olarak araştırmış, üst GiS semptomları olanlarda üst GiS hastalığı varlığını $\% 44,8$ olarak rapor etmiştir (8). Bizim çalışmamızda ise üst GiS semptomları nedeniyle hastaneye başvurarak konvansiyonel radyografi istenmiş 50 yaş üzeri 1126 hastanın \%55,2'sinde üst GiS patolojisi tespit ettik.

Üst GiS ile ilgili şikayetleri olan hastalarda radyografik olarak konulan tanılar; malignite, peptik ülser, hiatus hernisi, GÖR, tersiyer kontraksiyon, özofageal veb, akalazya, özofagus ve mide-duodenum divertikülü, kontur düzensizliği, opere olgular, hipotonik mide gibi bulguları içerebilmektedir. Biz bu çalışmamızda değerlendirmelerimizi yaparken malignite, peptik ülser, kaskad mide, gastrik volvulus, hipotonik mide gibi tanıları düşük oranda tespit ettiğimiz için, bu olguları tek maddede toplayarak hastalıkları sınıfladık. Malignite gibi tanılar ile ilgili şüphe mevcut olduğunda ekseriyetle endoskopi, bilgisayarlı tomografi veya manyetik rezonans incelemeleri ile tanı konması, skopide ise operasyon veya tedavi sonrası kontrol grafilerinin çekilmesi gibi nedenler bu sonuca yol açmış olabilir.

Gastroözofageal reflü yaşlılarda sıktır ve komplikasyonları yaşıda daha fazladır, atipik prezentasyon görülür. Yaşlılarda GÖR sıklığı \%10-20 arasında değişen oranlarda bildirilmektedir $(3,7)$. Dispepsisi olan 212 hastanın üst GiS endoskopilerini ve histopatolojik bulgularını araştıran retrospektif bir çalışmada; reflü özofajit \%8,5 hastada görülmüş, hastaların büyük bir çoğunluğunda normal duodenal mukoza tespit edilmiştir (12). Bu çalışmada; 45 yaşından daha yaşı ve daha genç hastalar olarak bulgular incelendiğinde yaşlı grupta, daha genç gruba göre anlamlı olarak daha fazla reflü özofajit saptanmıştır (sırasıyla, \%9,2 ve \%5). Bizim çalışmamızda GÖR \%9,8 hastada saptanmış, en sık 65-79 yaş arasında görülmüştür $(\% 11,7)$. Bu oran yaşlılarda gösterilen \%23 gibi oranlardan düşüktür (3). Sadece radyografik yöntemle konan tanıları almış olmamız bu sonuca neden olmuş olabilir. Epidemiyolojik çalışmalarda GÖR yönünden risk faktörleri obezite ve ileri yaştır $(12,13)$. Bu çalışmamızda GÖR'e neden olabilecek bu etkenleri retrospektif çalışma yöntemimiz nedeni ile hastalarımızda araştırmadık. Cinsiyete göre hastalıkları incelediğimizde çalışmamızda erkek cinsiyette GÖR daha fazla oranda tespit edilmiştir, ancak istatistiki olarak anlamlı bulunmamıştır $(p=0,924)$. Erkek cinsiyet GÖR için bir risk faktörüdür (14). Üst GiS semptomlarını 60 yaş üzeri hastalarda araştıran Pilotto ve arkadaşlarının yaptığı çalışmada ise; 
kadın cinsiyet üst GiS semptomları ile ilişkili bulunmuştur (8).

Çalışmamızda patolojik bulgular içerisinde ikinci sıklıkla tespit edilen tersiyer kontraksiyonlar kadınlarda \%10 gibi yüksek oranda, erkeklerde $\% 8,3$ oranında tespit edilirken, en sık 80 yaş ve üzerinde tespit edilmiştir (\%18). İleri yaşta özofagus ile ilgili sorunlar daha çok komorbiditeler ile ilişkilidir ve özofageal motilite ile ilgili çalışmalar çelişkili sonuçlar göstermiştir (3). Özofageal disfaji mevcut olduğunda, tümör gibi mekanik sorunlar, akalazya gibi nöromuskuler sorunlar, inflamatuar veya infeksiyöz sorunlar nedeniyle olabilir. Opere özofagus ve mide duodenum hastalıkları çalışmamızda patolojik bulgular arasında üçüncü sıklıkla $(\% 8,6)$ tespit edilmiştir (diğer bulgular az sayıda saptanan çeşitli patolojik bulgulardan oluştuğu için tartışımamıştır). Bu bulgu da radyografik tetkik istenen hastaların sıklıkla bir operasyon sonrası bu tetkik ile değerlendirilmeye alındığını, malignite, peptik ülser gibi tanıların endoskopi gibi yöntemlerle konulduğunu desteklemektedir. Çalışmamızda malign patolojik tanıların nadir olarak tespit edilmesi de bu sebeple olabilir. Yaşılıda değişen mikrobiata, azalan koruyucu mukozal mekanizmalar, azalan gastrik kanlanma ve bu değişikliklerden etkilenen tamir mekanizması yaş ilişkili gastrik değişikliklerdendir $(3,6,7)$. Bu değişiklikler yaşılları gastrik ülser gibi hastalıklara daha duyarlı hale getirir. En sık üçüncü patoloji olarak tespit ettiğimiz grubun opere olgular olması da bu bulguları destekler görünmektedir.

Çalışmamızda, hastaların mevcut komorbiditeleri ve kullandıkları ilaçlar gibi verilerin olmaması çalışmamızın zayıf yönüdür, ancak geniş hasta örneklemesi ile konvansiyonel yöntemlerle radyografik olarak konulan üst Gis patolojileri açısından önemli bir veri kaynağı oluşturmaktadır.

\section{Sonuç}

Ülkemizin epidemiyolojik verilerine katkıda bulunmayı amaçladığımız çalışmamızda en sık saptanan patolojik bulgular GÖR ve tersiyer kontraksiyon olmuştur. Yaş gruplarında en sık radyolojik bulgular; 50-64 yaş grubunda sırasıyla, normal bulgular, opere olgular ve GÖR; geriatrik yaş grubunda ise normal bulgular, tersiyer kontraksiyon ve GÖR olarak saptanmıştır. Yaş ilerledikçe tespit edilen normal bulgu oranı anlamlı şekilde azalırken, patolojik bulguların oranının arttığı görülmektedir. Geriatrik yaş grubunda tersiyer kontraksiyon, kontur düzensizliği, hiatus hernisi ve divertikül oranları 65 yaş altı gruba göre anlamlı olarak artış göstermiştir. İleri yaştaki hastalarda üst Gis semptomları varlığında bu bulgular ışığında tetkik ve tedavileri yönlendirmek uygun olacaktır.

Çıkar çatışması: Yazarlar arasında çıkar çatışması beyan edilmemiştir.

\section{Kaynaklar}

1. Bodner E. On the origins of ageism among older and younger adults. Int Psychogeriatr 2009; 21 (6): $1003-14$.

2. Ersanlı K, Kalkan M. Psikolojik, sosyal ve bedensel açıdan yaşılık. 1. Baskı. Ankara: Pegem Akademi Yayıncılık; 2008: 3.

3. Dumic I, Nordin T, Jecmenica M, Stojkovic Lalosevic M, Milosavljevic T, Milovanovic T. Gastrointestinal tract disorders in older age. Can J Gastroenterol Hepatol 2019; 6757524.doi:10.1155/2019/6757524

4. tuik.gov.tr [İnternet]. Yaş grubuna göre nüfus ve toplam nüfus içindeki oranı, 2007-2019 [01.03.2020 tarihinde ulaşılmıştır]. http://www.tuik.gov.tr/VeriBilgi.do?alt_id=1059\# adresinden alınmıştır.

5. OECD.org [homepage on the Internet]. OECD data [Cited17 December 2019]. Available from: https://data.oecd.org/pop/elderly-population.htm

6. Bhutto A, Morley JE. The clinical significance of gastrointestinal changes with aging. Curr Opin Clin Nutr Metab Care 2008; 11 (5): 651-60.

7. Crane SJ, Talley NJ. Chronic gastrointestinal symptoms in the elderly. Clin Geriatr Med 2007; 23 (4): 721-34.

8. Pilotto A, Maggi S, Noale M, Franceschi M, Parisi G, Crepaldi G. Association of upper gastrointestinal symptoms with functional and clinical characteristics in elderly. World J Gastroenterol 2011; 17 (25): 3020-6.

9. Maekawa T, Kinoshita Y, Okada A, et al. Relationship between severity and symptoms of reflux oesophagitis in elderly patients in Japan. J Gastroenterol Hepatol 1998; 13 (9): 927-30. 
10. Wallace MB, Durkalski VL, Vaughan J, et al. Age and alarm symptoms do not predict endoscopic findings among patients with dyspepsia: a multicentre database study. Gut 2001; 49 (1): 29-34.

11. Pilotto A, Addante F, D'Onofrio G, Sancarlo D, Ferrucci L. The Comprehensive geriatric assessment and the multidimensional approach. A new look at the older patient with gastroenterological disorders. Best Pract Res Clin Gastroenterol 2009; 23 (6): 829-37).

12. Piatek-Guziewicz A, Przybylska-Feluś M, Dynowski W, Zwolińska-Wcisło M, Lickiewicz J, Mach T. Endoscopic and histopathological findings of the upper gastrointestinal tract in patients with functional and organic dyspepsia. Przegl Lek 2014; 71 (4): 204-9.

13. Friedenberg FK, Xanthopoulos M, Foster GD, Richter JE. The association between gastroesophageal reflux disease and obesity. Am J Gastroenterol 2008; 103 (8): 2111-22.

14. Richter JE, Rubenstein JH. Presentation and epidemiology of gastroesophageal reflux disease. Gastroenterology 2018; 154 (2): 267-76. 